\title{
IMPACTO TRIBUTARIO EN EL SERVICIO DE TRANSPORTE TERRESTRE INTERPROVINCIAL DE PASAJEROS* El caso del retiro de la exoneración del IGV
}

\author{
Santiago Roca, Ph.D. \\ PROFESOR DE ECONOMÍA DE ESAN \\ sroca@esan.edu.pe \\ Luis Simabuko \\ INVESTIGADOR DE ESAN \\ 1simabu@esan.edu.pe \\ Jaime Dyer, M.A. \\ CONSULTOR DE ESAN \\ jdyer@ceoperu.com
}

\begin{abstract}
Resumen
Evalúa el impacto de la eliminación de la exoneración del IGV al servicio de transporte terrestre interprovincial de pasajeros -medida dispuesta en el 2003-a partir del análisis de la carga tributaria de las empresas del sector y el desarrollo de una simulación. Encuentra que, dadas las características de este mercado, en el que coexisten operadores formales e informales, las empresas formales asumirían el íntegro deI IGV, hecho que no sólo reduciría sensiblemente su rentabilidad y las expondría a una situación crítica, sino que perjudicaría también a los usuarios, cuya demanda se dirigiría a las empresas informales, con la consiguiente pérdida de calidad y seguridad en el servicio. Más aún, el propio Estado lograría un efecto contrario al deseado, ya que la recaudación fiscal sería menor a la que obtenía cuando estaba vigente la exoneración. Cabe señalar que, antes de transcurrido un año, el gobierno decidió restablecer la exoneración del IGV al servicio mencionado.
\end{abstract}

A mediados del 2003, con el fin de elevar la recaudación tributaria se eliminó la exoneración del IGV al servicio de transporte terrestre interprovincial de pasajeros (STTIP), sin considerar que este

* Este trabajo fue originalmente realizado a solicitud de la Confederación de Transportadores del Perú, Cotrap. Los autores y ESAN expresan su agradecimiento a José Navarrete Tapia, sector se encuentra sobrecargado de tributos y soporta la competencia de un amplio sector informal, que impide su adecuado desarrollo.

presidente de la Asociación de Propietarios de Ómnibus Interprovinciales del Perú (APOIP) y representante de la Cotrap, por autorizar la publicación de la presente versión revisada. 
El objetivo del presente estudio es evaluar el impacto de la aplicación del IGV al servicio de transporte terrestre interprovincial de pasajeros, para lo cual se propone analizar el nuevo equilibrio de mercado que se alcanzaría luego de decretarse esta medida.

Con este propósito, en la primera sección se calcula la carga tributaria y los diversos aportes sociales que enfrentan las empresas formales del sector. Luego, en la segunda sección se analizan los efectos de la aplicación del IGV al servicio de transporte interprovincial de pasajeros sobre: i) el equilibrio de mercado, ii) la rentabilidad de las empresas formales e informales, iii) la recaudación fiscal y, iv) el presupuesto y el bienestar de los usuarios. Finalmente, se presentan las conclusiones y recomendaciones del estudio.

\section{Cálculo de la carga tributaria que enfrentan las empresas formales}

Para estimar la carga tributaria que enfrentan las empresas formales del sector, incluidos los beneficios laborales y sociales, se procedió a trabajar los diversos rubros contables que componen la estructura de costos de las empresas; concretamente se estimó el peso relativo de cada ítem sobre las ventas o ingresos totales. Luego, cada ítem se ponderó, individualmente, por las correspondientes tasas tributarias a las que está afecto, con lo que finalmente se obtuvo la incidencia tributaria neta como porcentaje de los ingresos totales.

Para determinar la estructura de costos «típica» de las empresas de transporte, se analizó la información (al primer semestre del 2003) de cuatro de los princi- pales grupos empresariales del mercado: Expreso Cruz del Sur, Transportes Línea, Transportes Ormeño y Transportes Soyuz. Los resultados se presentan en el cuadro 1. Los costos están a valor de venta ( $\sin$ incluir IGV) $)^{1}$ y se ha separado, como costo aparte, el IGV pagado por las empresas y que no fuera utilizado como crédito fiscal hasta mediados del 2003.

Se debe recordar que hasta mediados del 2003, el servicio de transporte interprovincial de pasajeros se encontraba exonerado del IGV, pero no gozaban de este beneficio otros servicios que brindaban las empresas del sector, como el envío de encomiendas y servicios de transportes diversos. Asimismo, las compras que efectuaban estas empresas estaban afectas al íntegro del IGV, como las adquisiciones de insumos, servicios, bienes de capital, etc.

Como consecuencia de esto, luego de aplicado el crédito fiscal por las operaciones no exoneradas por las que se cobró IGV, queda un saldo de IGV no recuperado, que es parte del costo de las empresas y que, para efectos de análisis, se ha independizado en el ítem 24 del cuadro 1.

\subsection{Tributos y cargas diversas que afectan al sector}

Los tributos y contribuciones que afectan al sector se indican, de manera resumida, en el cuadro 2. Más adelante se analiza el impacto individual de cada uno de ellos sobre los respectivos rubros de costo de las empresas.

1. Los rubros detallados en este cuadro se trabajaron retirándoles previamente los impuestos y contribuciones diversas. 


\section{Cuadro 1 \\ Estructura de costos de las empresas formales*}

\begin{tabular}{|c|c|c|}
\hline & $\begin{array}{c}\text { En miles } \\
\text { de US\$ }\end{array}$ & $\begin{array}{c}\% \text { de } \\
\text { ingresos }\end{array}$ \\
\hline Ingresos & 33056,9 & $100,00 \%$ \\
\hline $\begin{aligned} & \text { Gastos de operación } \\
& 1 \text { Remuneraciones de choferes, ayudantes, supervisores, etc. } \\
& 2 \text { CTS, EsSalud, IES, aguinaldos, vacaciones y otros } \\
& 3 \text { Peajes } \\
& 4 \text { Combustibles } \\
& 5 \text { Lubricantes } \\
& 6 \text { Repuestos } \\
& 7 \text { Neumáticos, cámaras y ponchos } \\
& 8 \text { Reparación y mantenimiento } \\
& 9 \text { Seguros } \\
& 10 \text { Depreciación } \\
& 11 \text { Otros gastos de operación }\end{aligned}$ & $\begin{array}{r}1601,3 \\
726,7 \\
1002,1 \\
8530,4 \\
244,8 \\
2422,9 \\
527,2 \\
86,0 \\
522,4 \\
4256,4 \\
1948,6 \\
22642,9\end{array}$ & $\begin{array}{r}4,84 \% \\
2,20 \% \\
3,03 \% \\
25,81 \% \\
0,74 \% \\
7,33 \% \\
1,59 \% \\
2,60 \% \\
1,58 \% \\
12,88 \% \\
5,89 \% \\
68,50 \%\end{array}$ \\
\hline $\begin{array}{l}\text { Gastos administrativos } \\
12 \text { Sueldos } \\
13 \text { CTS, EsSalud, IES, aguinaldos, vacaciones y otros } \\
14 \text { Honorarios profesionales } \\
15 \text { Servicios prestados por terceros } \\
16 \text { Útiles de escritorio } \\
17 \text { Mantenimiento local } \\
18 \text { Depreciación activos administrados } \\
19 \text { Alquileres de oficinas } \\
20 \text { Seguros } \\
21 \text { Otros gastos }\end{array}$ & $\begin{array}{r}1310,3 \\
558,5 \\
211,8 \\
279,2 \\
99,1 \\
179,1 \\
171,0 \\
406,7 \\
36,1 \\
1393,7 \\
4645,4 \\
\end{array}$ & $\begin{array}{r}3,96 \% \\
1,69 \% \\
0,64 \% \\
0,84 \% \\
0,30 \% \\
0,54 \% \\
0,52 \% \\
1,23 \% \\
0,11 \% \\
4,22 \% \\
\mathbf{1 4 , 0 5 \%} \\
\end{array}$ \\
\hline $\begin{array}{l}\text { Gastos financieros } \\
22 \text { Gastos financieros }\end{array}$ & 1422,1 & \\
\hline $\begin{array}{l}\text { Otros gastos/ingresos } \\
23 \text { Otros gastos }\end{array}$ & 866,2 & $2,62 \%$ \\
\hline 24 IGV no utilizado (costo en operaciones no gravadas) & 2500,5 & $7,56 \%$ \\
\hline Costos totales antes de impuestos & 32077,2 & $97,04 \%$ \\
\hline Utilidad antes de impuestos** & 1601,1 & $4,84 \%$ \\
\hline 25 Participación utilidad trabajadores & 80,1 & $0,24 \%$ \\
\hline Utilidad después de participación de trabajadores & 1521,0 & $4,60 \%$ \\
\hline 26 Impuesto a la renta (IR): $27 \%$ & 410,7 & $1,24 \%$ \\
\hline
\end{tabular}

* Basada en la información de Cruz del Sur, Línea, Ormeño y Soyuz.

** La utilidad real o económica antes de impuestos de las cuatro empresas asciende a US\$979 704. Sin embargo, la utilidad con fines tributarios, es decir, para el cálculo del impuesto a la renta, es la indicada en el cuadro respectivo, ya que sólo considera las utilidades y no las pérdidas. Dos de los cuatro grupos empresariales arrojaron pérdidas; no hubo reparto de utilidades a los trabajadores ni pago del impuesto a la renta. 


\section{Cuadro 2 \\ Tributos y contribuciones por rubro}

\begin{tabular}{|c|c|}
\hline Rubros de costo & Tasa \\
\hline $\begin{array}{l}\text { Gastos de operación } \\
1 \text { Remuneraciones de choferes, ayudantes, supervisores, etc. } \\
2 \text { CTS, EsSalud, IES, aguinaldos, vacaciones y otros } \\
3 \text { Peajes } \\
4 \text { Combustibles } \\
5 \text { Lubricantes } \\
6 \text { Repuestos } \\
7 \text { Neumáticos, cámaras y ponchos } \\
8 \text { Reparación y mantenimiento } \\
9 \text { Seguros } \\
10 \text { Depreciación } \\
11 \text { Otros gastos de operación }\end{array}$ & $\begin{array}{l}\text { Ninguna } \\
44,32 \% \text { remuneraciones } \\
\text { Tarifa por eje (entre S/. } 2 \text { y } \\
\text { S/. } 7,5) \\
\text { S/.2,29 x gl. }(36,9 \% \text { del } \\
\text { valor de venta + IGV) } \\
\text { Arancel } 12 \%+\text { IGV } \\
\text { Arancel } 7 \%+\text { IGV } \\
\text { Arancel } 12 \%+\text { IGV } \\
\text { IGV } \\
3 \%+\text { IGV } \\
\text { Arancel } 12 \%+\text { IGV } \\
\text { IGV }\end{array}$ \\
\hline $\begin{array}{l}\text { Gastos administrativos } \\
12 \text { Sueldos } \\
13 \text { CTS, EsSalud, IES, aguinaldos, vacaciones y otros } \\
14 \text { Honorarios profesionales } \\
15 \text { Servicios prestados por terceros } \\
16 \text { Útiles de escritorio } \\
17 \text { Mantenimiento local } \\
18 \text { Depreciación activos administrados } \\
19 \text { Alquileres de oficinas } \\
20 \text { Seguros } \\
21 \text { Otros gastos }\end{array}$ & $\begin{array}{l}\text { Ninguna } \\
44,32 \% \text { remuneraciones } \\
\text { IR + IES } \\
\text { IGV } \\
\text { IGV } \\
\text { IGV } \\
\text { Ninguna } \\
\text { Ninguna } \\
3 \%+\text { IGV } \\
\text { Impuesto predial / IGV }\end{array}$ \\
\hline $\begin{array}{l}\text { Gastos financieros } \\
22 \text { Gastos financieros }\end{array}$ & \\
\hline $\begin{array}{l}\text { Otros gastos/ingresos } \\
23 \text { Otros gastos }\end{array}$ & \\
\hline 24 IGV no utilizado (costo en operaciones no gravadas) & $18 \%$ de compras \\
\hline Utilidad antes de impuestos & \\
\hline 25 Participación utilidad trabajadores & $5 \%$ de utilidad \\
\hline Utilidad después de participación de trabajadores & \\
\hline 26 Impuesto a la renta: $27 \%$ & $27 \%$ de utilidad \\
\hline
\end{tabular}

Fuentes: SUNAT, MEM, INEI. 


\section{El impuesto selectivo al consumo (ISC) a los combustibles}

El D.S. N. ${ }^{\circ}$ 083-2003-EF, de junio del 2003, modificó los valores del ISC a los combustibles, aplicando al diesel 2 un tributo de 2,29 soles por galón, con lo cual el precio al público fue de 7,39 soles (incluido el IGV), según la estructura que se muestra a continuación.

Es evidente que la carga tributaria que enfrenta el sector es muy elevada (ver análisis comparativo con otros sectores en el recuadro de la página siguiente), ya que afecta al combustible, el insumo más importante de esta actividad. Así, el ISC representa el $31 \%$ del precio al público, mientras el IGV representa el $16 \%$; es decir, de cada 100 soles que se paga por este combustible 47 soles corresponden a impuestos.
Dado que en la estructura de costos se ha trabajado sobre valores de venta, se utiliza el porcentaje que el ISC representa sobre el valor de venta del diesel 2, que asciende a $36,9 \%$. Este ratio se aplica al ítem 4 del cuadro 1, con lo cual se obtiene la incidencia tributaria neta del ISC a los combustibles, que alcanza a $6,95 \%$ de los ingresos.

\section{Aranceles}

Ante la casi inexistente producción nacional de ómnibus, se puede asumir que todas las unidades formales del STTIP son importadas (principalmente del Brasil) y, por ende, están gravadas con un arancel de $12 \%$, más el IGV correspondiente. En el caso de ser unidades usadas, se les aplica un ISC del $30 \%$, excepto si son compradas a través de los Ceticos. Así, el arancel considerado para las importaciones de

\section{Composición del precio del diesel 2}

\begin{tabular}{|l|c|c|c|}
\hline Elementos del precio & $\begin{array}{c}\text { Soles } \\
\text { por galón }\end{array}$ & $\begin{array}{c}\text { Porcentaje sobre } \\
\text { precio al público }\end{array}$ & $\begin{array}{c}\text { Porcentaje sobre } \\
\text { valor de venta } \\
\text { al público }\end{array}$ \\
\hline Precio neto Petroperú & 3,54 & $47,9 \%$ & $57,0 \%$ \\
+ ISC & 2,29 & $31,0 \%$ & $36,9 \%$ \\
= Valor venta ex planta Callao & 5,83 & $78,9 \%$ & $93,9 \%$ \\
+ Margen comercial & 0,38 & $5,1 \%$ & $6,1 \%$ \\
= Valor venta al público & 6,21 & $84,0 \%$ & $100,0 \%$ \\
+ IGV & 1,18 & $16,0 \%$ & \\
= Precio al público & 7,39 & $100,0 \%$ & \\
\hline
\end{tabular}

Fuente: MEM.

Incidencia tributaria neta del ISC

\begin{tabular}{|l|c|c|}
\hline \begin{tabular}{l|l|} 
Total combustibles \\
(en miles de US\$)
\end{tabular} & 8530,4 & Incidencia tributaria neta: \\
\cline { 1 - 2 } Valor neto combustibles & 6232,0 & \\
\hline ISC: $36,9 \%$ de valor de venta & 2298,4 & $6,95 \%$ sobre los ingresos \\
\hline
\end{tabular}




\section{IMPACTO DEL PRECIO DE LOS COMBUSTIBLES SOBRE LAS ACTIVIDADES ECONÓMICAS}

Alrededor del $12 \%$ de los ingresos fiscales en el país dependen de la recaudación del ISC a los combustibles, por lo que el aumento del precio de los hidrocarburos suele ser una medida tendiente a equilibrar las cuentas fiscales. Según estimados del Ministerio de Economía y Finanzas², sobre la base de la Tabla Insumo-Producto (Base 1994), se calcula que el sector transportes y comunicaciones es el segundo más afectado por estas alzas, sólo superado por la actividad pesquera, que puede, sin embargo, acceder a ciertos beneficios tributarios que compensa este impacto negativo. Así, por ejemplo, si el precio de los combustibles crece en $100 \%$, se estima que los costos de los insumos en la actividad de transportes y comunicaciones aumentarían en $25 \%$. Si bien estos estimados son bastante gruesos, ya que no separa la actividad de transporte del de comunicaciones, y, por lo tanto, es de esperar que el impacto sobre la actividad de transporte sea más elevada que el $25 \%$ estimado, se confirma la premisa que la actividad de transporte terrestre interprovincial de pasajeros es particularmente sensible al alza del ISC a los combustibles, todo lo cual evidencia que esta actividad se encuentra entre los más gravados tributariamente.

\section{Aumento en el costo de los insumos ante un aumento de $100 \%$ del precio de los combustibles (\%)}

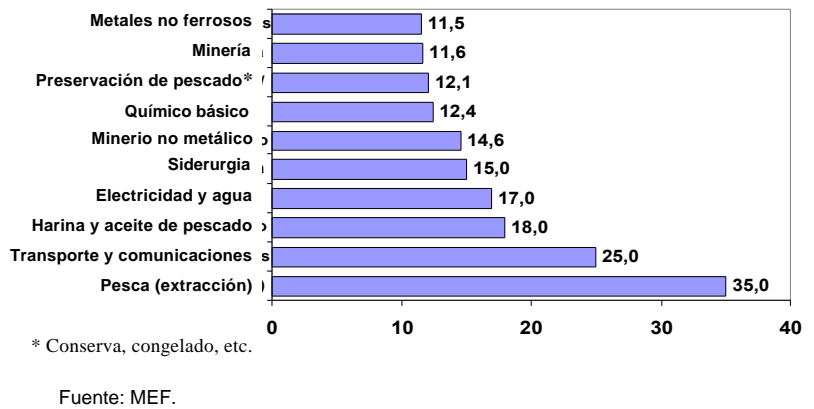

2. MEF. Informe situacional y problemática actual del petróleo en el mercado doméstico. Boletín de Transparencia Fiscal- Informe Especial. 


\begin{tabular}{|l|r|l|}
\hline $\begin{array}{l}\text { Total depreciación } \\
\text { (en miles de US\$) }\end{array}$ & 4256,4 & Incidencia tributaria neta: \\
\cline { 1 - 2 } Valor depreciación sin efecto arancel & 3800,4 & \\
\cline { 1 - 2 } $\begin{array}{l}\text { Valor arancel: } 12 \% \text { a ómnibus } \\
\text { (depreciación) }\end{array}$ & 456,0 & $1,38 \%$ sobre los ingresos \\
\hline
\end{tabular}

ómnibus se aplica únicamente sobre la depreciación de las unidades (ver ítem 10 del cuadro 2).

Adicionalmente, la importación de motores diesel, repuestos y cámaras está afecta a una tasa de 7\%; mientras otros productos, como llantas para ómnibus, vidrios-ventanas, aceites-lubricantes, grasas, alfombras de plástico para ómnibus, juntas-empaquetaduras diversas, guarniciones para frenos y embragues (amianto), herrajes para vehículos, baterías, pagan una tasa de $12 \%$ por su importación.

De esta manera, volviendo al cuadro 1, para los lubricantes (ítem 5) la tasa ad valorem es de $12 \%$, para los neumáticos y cámaras (ítem 7) se ha asumido la tasa de $12 \%$ (porque la tasa correspondiente a las llantas es la de mayor costo) y a repuestos en general (ítem 6) se le asigna, conservadoramente, la tasa de $7 \%$.

Según lo informado por las empresas, se ha determinado que el $70 \%$ de los lubricantes, el $80 \%$ de los neumáticos y el $90 \%$ de los repuestos son importados. Estas compras pagan los correspondientes aranceles ad valorem, por lo que el efecto neto de dichos ítem está también ponderado por esos porcentajes.

Considerando estos rubros -lubricantes, repuestos y neumáticos-, se estima que la incidencia tributaria neta debido a los aranceles alcanzaría el 0,63\% de los ingresos.

\begin{tabular}{|l|r|l|}
\hline Total lubricantes (en miles de US\$) & 244,8 & \multirow{2}{*}{ Incidencia tributaria neta: } \\
\cline { 1 - 2 } Valor lubricantes sin efecto arancel & 225,8 & \\
\hline Valor arancel: $12 \%$ al $70 \%$ del total & 19,0 & $0,06 \%$ sobre los ingresos \\
\hline
\end{tabular}

\begin{tabular}{|l|r|l|}
\hline Total repuestos (en miles de US\$) & 2422,9 & \multirow{2}{*}{ Incidencia tributaria neta: } \\
\cline { 1 - 2 } Valor repuestos sin efecto arancel & 2279,3 & \\
\hline Valor arancel: $7 \%$ al $90 \%$ del total & 143,6 & $0,43 \%$ sobre los ingresos \\
\hline
\end{tabular}

\begin{tabular}{|l|r|r|}
\hline Total neumáticos (en miles de US\$) & 527,2 & \multirow{2}{*}{ Incidencia tributaria neta: } \\
\cline { 1 - 2 } Valor Neumáticos sin efecto arancel & 481,0 & \\
\hline Valor arancel: $12 \%$ al $80 \%$ del total & 46,2 & $0,14 \%$ sobre los ingresos \\
\hline
\end{tabular}




\section{Impuesto general a las ventas (IGV)}

Este impuesto está regido por el Texto Único Ordenado (TUO) de la Ley del IGV e ISC, vigente desde el 16 de abril de 1999. Según el artículo 69 de esta norma, el IGV no constituye ni gasto ni costo para efectos de la aplicación del impuesto a la renta, cuando se tenga derecho a utilizarlo como crédito fiscal.

Todas las adquisiciones de las empresas han estado afectas al IGV, pero como es conocido, los pasajes interprovinciales por vía terrestre estaban exonerados del IGV hasta el 16 de junio de 2003; de modo que hasta esa fecha el IGV pagado en todas las compras realizadas era asumido por las empresas como parte del costo de sus compras (no existía recuperación del crédito fiscal por los pasajes vendidos).

Como se trataba de una actividad exonerada, contablemente era obligatorio que el IGV se registrara como costo, conjuntamente con el valor de venta del producto como un todo. Para los fines de este estudio, las empresas analizadas han independizado los valores de venta del IGV pagado pero no recuperado. De este modo, el ítem 24 mide la incidencia tributaria neta del impuesto general a las ventas o IGV. La tasa del IGV vigente actualmente es de $19 \%$.

\section{Aportaciones sociales}

Las empresas están sujetas a las siguientes aportaciones y contribuciones sociales:

- EsSalud: 9\% de la remuneración mensual.
- Impuesto Extraordinario de Solidaridad, IES: $2 \%$ de la remuneración mensual.

- Vacaciones: una remuneración por año (equivalente al 8,33\% de la remuneración mensual).

- Compensación por Tiempo de Servicio, CTS: una remuneración por año (equivalente al $8,33 \%$ de la remuneración mensual).

- Aguinaldos por Fiestas Patrias y Navidad: una remuneración por año en cada caso (equivalentes al $16,66 \%$ de la remuneración mensual).

Estos conceptos representan una carga adicional efectiva de $44,3 \%$ sobre la remuneración del trabajador, la que se está contabilizando en los ítem 2 y 13 del cuadro 1 , bajo el rubro específico de contribuciones, aportaciones, beneficios sociales, vacaciones y otros.

\section{Participación de los trabajadores en las utilidades}

Los trabajadores de cada empresa de transporte interprovincial reciben, en conjunto, el $5 \%$ de la utilidad neta obtenida en el ejercicio. Este valor se aplica íntegramente en el ítem 25 del cuadro 1.

\section{Peajes}

La principal administradora de peajes es Provías Nacional, que maneja 52 de los 61 peajes del ámbito nacional. En teoría los peajes se determinan sobre la base del tránsito y los costos de mantenimiento de las vías. La tarifa de equilibrio recomen- 
dada que debe alcanzarse en el 2004 es de 5,45 soles por eje o de 10,90 soles por eje de ida y vuelta; sin embargo, los transportistas gozan de un descuento de 1 sol sobre esa tarifa por eje.

Desde el 1 de agosto de 2003 los peajes desde Lima a cualquier dirección son de 7,50 soles por eje, y no se cobran por la ruta de vuelta; con la particularidad de la aplicación de un descuento de 1 sol para los transportistas inscritos en el MTC.

Respecto a las otras administradoras de peajes, Emape cobra de ida y vuelta. En los peajes de Circunvalación, Chillón y Huaylas se paga 2 soles por eje, mientras en el de Villa, hacia el sur, se paga 2,50 soles por eje.

En lo que se refiere a las concesionarias privadas:

- Concar cobra en los peajes de la Variante de Uchumayo y de Matarani.

- Norvial cobra 4,50 por eje, para cada vía, en los peajes de la Variante de Pasamayo, del Serpentín de Pasamayo y de Paraíso (Huacho).

Sólo por poner un ejemplo, en términos generales un ómnibus de doble eje que cubre la ruta Lima-Ica termina pagando por viaje un total de 73,50 soles por peajes, mientras que si es de eje simple paga 49,00 soles.

Si bien los peajes son aportes obligatorios en contraprestación al servicio de mantenimiento de las carreteras, en la realidad el gobierno los ha tratado como un impuesto, pues destina los fondos recaudados a fines distintos. Según el Ministerio de Transportes y Comunicaciones ${ }^{3}$, en
1997 y 1998 sólo el $28 \%$ de estos recursos se utilizó en el mantenimiento de carreteras; el mayor porcentaje, $72 \%$, se destinó a la rehabilitación de los daños ocasionados por el fenómeno El Niño.

Teniendo en consideración estos hechos, en este trabajo se ha incluido el peaje como un impuesto o contribución adicional. Por ello, el íntegro del valor de los pagos por peajes, especificado en el ítem 3 del cuadro 1 , forma parte de la carga tributaria que enfrentan las empresas formales del sector.

\section{Contribuciones municipales}

Las oficinas, estaciones, talleres y demás instalaciones de las empresas de transportes están afectas al pago de arbitrios municipales, impuesto predial y otras contribuciones que varían de municipio a municipio y que dependen del valor de los predios. Las tasas anuales del impuesto predial son las siguientes:

\begin{tabular}{|c|c|c|}
\hline Hasta 15 UIT & $>15$ UIT < $<60$ UIT & $>60$ UIT \\
\hline $0,20 \%$ & $0,60 \%$ & $1,00 \%$ \\
\hline
\end{tabular}

El impuesto predial se calculó a partir de los valores de los terrenos y edificaciones de las empresas (datos proporcionados por ellas mismas). Dado que se asume que el valor de los bienes inmuebles supera las 60 UIT (54 mil dólares) y que durante el ejercicio 2003 la UIT se fijó en 3100 soles, se aplicó a las empresas la tasa más alta. El efecto neto es equivalente al $0,73 \%$ de los ingresos, el que se in-

3. Banco Mundial. Perú policy notes 2000. Background papers. 
cluyó en el ítem 21 del cuadro 1 como parte de «otros gastos administrativos».

\section{Impuesto a la renta}

En cuanto al impuesto a la Renta, las empresas de transporte están afectas a la tasa del $27 \%$ sobre las utilidades brutas del ejercicio. En el ítem 26 del cuadro 1 se aplica íntegramente la tasa mencionada, con lo que se hace explícito el peso de este tributo sobre la estructura de costos.

\section{Derechos de emisión de pólizas de seguros}

Los transportistas adquieren seguros de vida para sus pasajeros y seguros patrimoniales para sus activos, además del SOAT, Seguro Obligatorio de Accidentes de Tránsito, obligatorio desde mediados del año 2002.

Todo seguro está afecto a una tasa de $3 \%$ por derecho de emisión, independientemente de la empresa de seguros. Si bien esta tasa no es una contribución o impuesto se está asumiendo como tal, ya que se aplica con el concepto de «traslado» a los asegurados de ciertos aportes o contribuciones que efectivamente pagan las compañías de seguros a la Superintendencia de Banca y Seguros (SBS). Estos gastos se han colocado en los ítem 9 y 20 del cuadro 1; su incidencia neta se obtiene de aplicar la tasa correspondiente: $3 \%$.

\subsection{Incidencia de la carga tributaria entre las empresas formales}

De acuerdo con la estructura de costos de las empresas analizadas, se procedió a aplicar la tasa impositiva para cada rubro, según lo explicado en la sección anterior. Se obtuvo así la incidencia de las cargas tributarias y diversos aportes a los que están afectas las empresas formales del sector.

Tal como se muestra en el cuadro 3, la incidencia tributaria promedio estimada para las empresas formales del sector en estudio (STTIP) equivale al $25,75 \%$ de sus ingresos, porcentaje ligeramente inferior al calculado en el estudio de peajes realizado por la Universidad del Pacífico en el 2001 -obviamente, con propósitos, metodología, muestra y periodos de análisis distintos a los nuestros-.

Como puede observarse en el gráfico 1, la incidencia de los impuestos indirectos (IGV, ISC y aranceles) es la mayor y alcanza el 16,5\% de los ingresos. Estos impuestos son por mucho la principal carga tributaria que deben enfrentar estas

\begin{tabular}{|l|c|c|c|c|}
\hline & Operación & $\begin{array}{c}\text { Incidencia } \\
\text { tributaria neta: }\end{array}$ & Administrativo & $\begin{array}{c}\text { Incidencia } \\
\text { tributaria neta: }\end{array}$ \\
$\begin{array}{l}\text { Total seguros } \\
\text { (en miles de US\$) }\end{array}$ & 522,4 & & 36,0 & \\
\cline { 1 - 2 } $\begin{array}{l}\text { Valor seguros sin } \\
\text { derechos emisión }\end{array}$ & 507,2 & & 35,0 & \\
\hline Derecho de emisión & 15,2 & $0,05 \%$ & 1,0 & $0,00 \%$ \\
\hline
\end{tabular}




\section{Cuadro 3 \\ Incidencia tributaria}

\begin{tabular}{|c|c|}
\hline Ítem & $\begin{array}{c}\text { Incidencia neta } \\
\text { sobre los ingresos }\end{array}$ \\
\hline Ingresos & $100,00 \%$ \\
\hline $\begin{array}{l}\text { Gastos de operación } \\
1 \text { Remuneraciones de choferes, ayudantes, supervisores, etc. } \\
2 \text { CTS, EsSalud, IES, aguinaldos, vacaciones y otros } \\
3 \text { Peajes } \\
4 \text { Combustibles } \\
5 \text { Lubricantes } \\
6 \text { Repuestos } \\
7 \text { Neumáticos, cámaras y ponchos } \\
8 \text { Reparación y mantenimiento } \\
9 \text { Seguros } \\
10 \text { Depreciación } \\
11 \text { Otros gastos de operación }\end{array}$ & $\begin{array}{l}0,00 \% \\
2,20 \% \\
3,03 \% \\
6,95 \% \\
0,06 \% \\
0,43 \% \\
0,14 \% \\
0,00 \% \\
0,05 \% \\
1,38 \% \\
0,00 \%\end{array}$ \\
\hline $\begin{array}{l}\text { Gastos administrativos } \\
12 \text { Sueldos } \\
13 \text { CTS, EsSalud, IES, aguinaldos, vacaciones y otros } \\
14 \text { Honorarios profesionales } \\
15 \text { Servicios prestados por terceros } \\
16 \text { Útiles de escritorio } \\
17 \text { Mantenimiento local } \\
18 \text { Depreciación activos administrados } \\
19 \text { Alquileres de oficinas } \\
20 \text { Seguros } \\
21 \text { Otros gastos }\end{array}$ & $\begin{array}{l}0,00 \% \\
1,69 \% \\
0,00 \% \\
0,00 \% \\
0,00 \% \\
0,00 \% \\
0,00 \% \\
0,00 \% \\
0,00 \% \\
0,73 \%\end{array}$ \\
\hline $\begin{array}{l}\text { Gastos financieros } \\
22 \text { Gastos financieros }\end{array}$ & $0,00 \%$ \\
\hline $\begin{array}{l}\text { Otros gastos/ingresos } \\
23 \text { Otros gastos }\end{array}$ & $0,00 \%$ \\
\hline 24 IGV no utilizado (costo en operaciones no gravadas) & $7,56 \%$ \\
\hline Costos totales antes de impuestos & \\
\hline Utilidad antes de impuestos & $0,00 \%$ \\
\hline 25 Participación utilidad trabajadores & $0,24 \%$ \\
\hline 26 Impuesto a la renta: $27 \%$ & $1,24 \%$ \\
\hline 27 Contribuciones totales & $25,75 \%$ \\
\hline
\end{tabular}




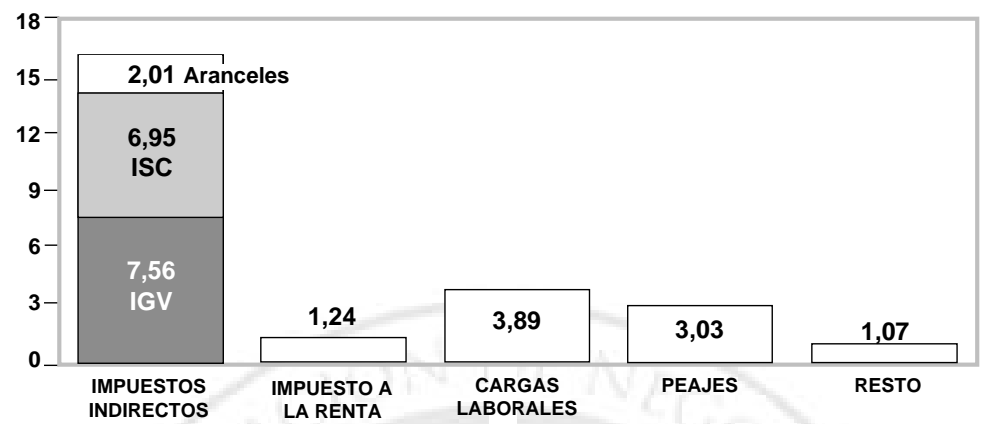

Incidencia tributaria por principales impuestos (\% de ingresos) Gráfico 1

empresas, al representar el $64 \%$ del total. Bastante más rezagados, les siguen las cargas laborales y sociales del personal, los peajes y el impuesto a la renta.

\section{Impacto de la aplicación del IGV al STTIP}

En la presente sección se estima el impacto de la aplicación del IGV al servicio de transporte interprovincial de pasajeros, específicamente se analiza el impacto de esta medida en cuatro aspectos: i) el equilibrio del mercado, ii) la rentabilidad de las empresas formales e informales del sector, iii) la recaudación fiscal y iv) el presupuesto y bienestar de los usuarios. El análisis gira en torno a estimar qué agente económico pagaría finalmente el IGV, para ello se propone definir el nuevo equilibrio del mercado teniendo en cuenta la existencia del amplio sector informal.

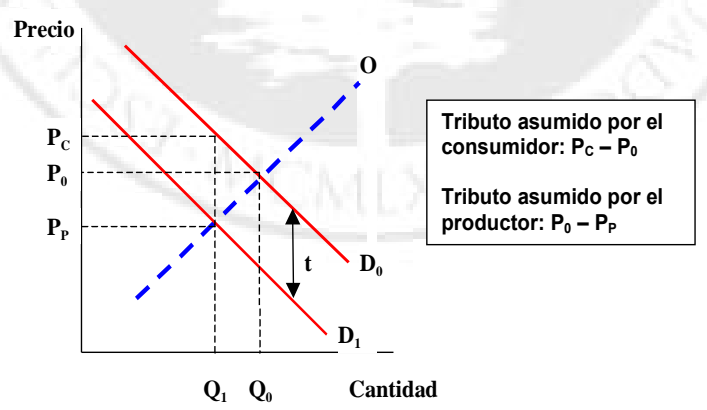

Distribución de la carga impositiva entre consumidores y productores Gráfico 2 


\subsection{Impacto sobre el equilibrio del mercado}

\subsubsection{Aspectos teóricos}

De acuerdo con la teoría económica, los impuestos que crea el gobierno pueden imponerse a los compradores o a los productores. No obstante, qué agente económico soportará en última instancia esta carga dependerá de las condiciones específicas del mercado, es decir, obedecerá a las condiciones de la oferta y de la demanda. Para estudiar las implicancias de un determinado impuesto se debe definir: i) si la disposición legal afecta a la curva de oferta o a la curva de demanda; ii) hacia dónde se desplazaría la curva afectada y iii) definir el nuevo equilibrio del mercado.

En el caso que estamos analizando, y como puede observarse en el gráfico 2, el impuesto afectaría legalmente a los consumidores, por lo que la curva de deman- da se desplazaría hacia abajo en la proporción definida por la tasa impositiva «t». Debido a la aplicación del impuesto, se produciría un divorcio entre el precio al consumidor $\left(\mathrm{P}_{\mathrm{C}}\right)$ y el precio al productor $\left(\mathrm{P}_{\mathrm{P}}\right)$. El precio que pagarían los compradores se incrementaría, mientras que el precio que recibirían los productores disminuiría.

El análisis de incidencia de los tributos sostiene que ambos, compradores y productores, suelen cargar con el impuesto, pero ¿cuál de ellos soportará la mayor parte del impuesto? La respuesta se encuentra en la elasticidad precio de la demanda. Si la demanda es inelástica, la mayor carga fiscal recaería sobre los compradores; en cambio, si la demanda es elástica, la carga fiscal recaería principalmente sobre los productores.

En el gráfico 3 pueden observarse dos curvas de demanda de diferentes elasticidades. La demanda más elástica, la figu-

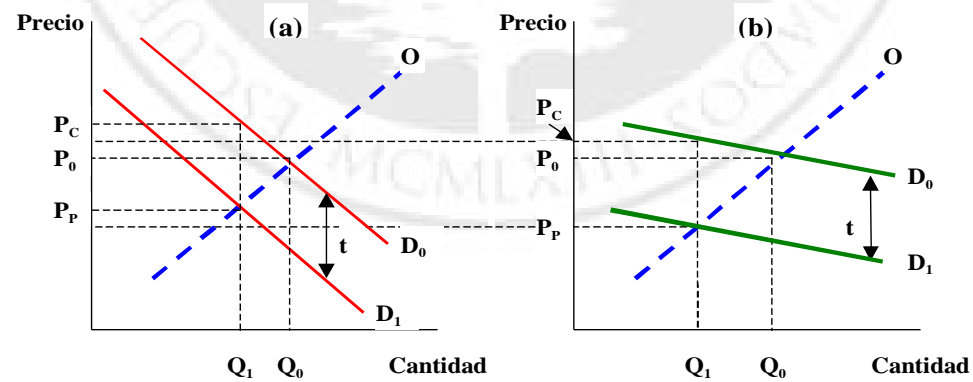

Distribución de la carga impositiva por niveles de elasticidad de la demanda Gráfico 3 
ra del lado derecho (b), determinaría que el precio al consumidor fuera menor que el precio que pagaría si la demanda fuera la de la figura de la izquierda (a), con lo cual el tributo asumido por el consumidor $\left(\mathrm{P}_{\mathrm{C}}-\mathrm{P}_{0}\right)$ sería menor; por el contrario, en la figura de la derecha el precio al productor sería menor, con lo cual el tributo asumido por el productor $\left(\mathrm{P}_{0}-\mathrm{P}_{\mathrm{P}}\right)$ sería mayor.

\subsubsection{Evidencia empírica}

Si bien no se cuenta con una amplia información histórica para calcular una curva de demanda por servicios de transporte terrestre interprovincial de pasajeros, si es posible definir ciertos rangos de magnitud de la elasticidad precio de la demanda.

El cuadro 4 detalla la evolución de la tarifa y el porcentaje de ocupación de una de las empresas formales analizadas. Puede advertirse que el inicial incremento de la tarifa de transporte en el mes de julio de 2003 (en comparación a julio del 2002) generó tal descenso de la demanda que la empresa se vio obligada en los siguientes meses a moderar este incremento con el fin de no perder mayor participación en el mercado.

No obstante, el retroceso posterior de los precios (agosto y setiembre con relación a julio del 2003) no parece haber tenido efectos positivos, ya que no ha logrado revertir la pérdida en la participación del mercado. Este fenómeno es un claro indicio de que el comportamiento y reacomodo del mercado no es típico, debido fundamentalmente a la existencia de un gran sector informal.

Los datos contenidos en el cuadro indican que en el mes de julio (en compara- ción a julio del 2002), la elasticidad precio promedio fue de $-0,87$, lo que significa que por cada sol de incremento de la tarifa, la tasa de ocupación cae en 0,87 puntos porcentuales. No obstante, para los meses siguientes se estiman elasticidades de $-2,30$ y $-4,62$, respectivamente, con lo cual el promedio de todo el periodo de análisis asciende $\mathrm{a}-1,899$.

En todos los casos, una vez pasado el impacto inicial en el mes de julio (mes donde la demanda es estacionalmente más elevada y, por lo tanto, el impacto del incremento de la tarifa tiende a neutralizarse) la caída de la demanda es proporcionalmente mayor que el incremento de la tarifa, por lo que hay claros indicadores de que las empresas formales del sector enfrentan una curva de demanda bastante elástica. De manera gruesa, y en un escenario un tanto conservador, se puede considerar que la elasticidad promedio sería negativa en 1,899 , lo que significa que por cada sol de incremento de la tarifa, la tasa de ocupación caería en casi 2 puntos porcentuales.

Se puede trazar una hipotética curva de demanda, como la que se muestra en el gráfico 4, a partir de los indicadores de elasticidad $(-1,899)$, la tarifa $(45,8)$ y el porcentaje de ocupación (84), relacionados por la siguiente ecuación:

$\%$ de ocupación $=84-1,899$ * $($ tarifa $-45,8)$

De acuerdo con la curva trazada, si el precio crece de 45,8 soles (nivel base) a 54,5 soles, la demanda caería de $84,3 \%$ (nivel base) a 67,8\% de ocupación. En términos proporcionales, si la tarifa crece en $19 \%$ (lo que implicaría la transferencia total del IGV), la cantidad demandada caería en $19,6 \%$ (de $84,3 \%$ a $67,8 \%$ de 


\section{Cuadro 4 \\ Comportamiento de la demanda*}

\begin{tabular}{|c|c|c|c|c|c|c|c|c|}
\hline & \multicolumn{4}{|c|}{ Tarifa promedio (soles) $* *$} & \multicolumn{3}{|c|}{$\%$ de ocupación de las unidades } & \multirow{3}{*}{$\begin{array}{c}\text { Elasticidad } \\
\text { B/A }\end{array}$} \\
\hline & \multirow[b]{2}{*}{2002} & \multirow[b]{2}{*}{2003} & \multicolumn{2}{|c|}{ Variación } & \multirow[b]{2}{*}{2002} & \multirow[b]{2}{*}{2003} & \multirow{2}{*}{$\begin{array}{c}\text { Variación } \\
\text { (B) }\end{array}$} & \\
\hline & & & (A) & $(\%)$ & & & & \\
\hline Julio & 46,5 & 55,7 & 9,2 & $20 \%$ & 85 & 77 & $-8,0$ & $-0,8696$ \\
\hline Agosto & 47,1 & 53,2 & 6,1 & $13 \%$ & 87 & 73 & $-14,0$ & $-2,2951$ \\
\hline Setiembre & 43,7 & 46,3 & 2,6 & $6 \%$ & 81 & 69 & $-12,0$ & $-4,6154$ \\
\hline Promedio & 45,8 & 51,7 & 6,0 & $13 \%$ & 84 & 73 & $-11,0$ & $-1,8994$ \\
\hline
\end{tabular}

* Correspondiente a una de las empresas formales analizada.

** Servicio básico o intermedio.

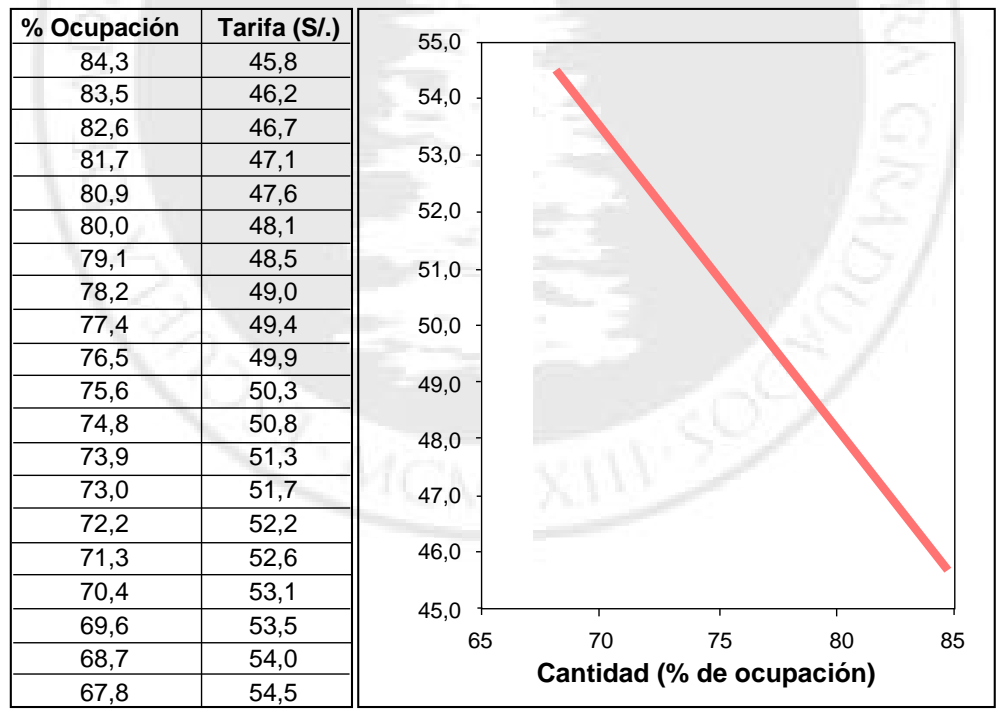




\begin{tabular}{|c|c|}
\hline $\begin{array}{c}\text { Transferencia } \\
\text { del IGV al } \\
\text { consumidor }\end{array}$ & $\begin{array}{c}\text { Variación } \\
\text { del ingreso }\end{array}$ \\
\hline $0 \%$ & $-19,0 \%$ \\
\hline $1,0 \%$ & $-19,0 \%$ \\
\hline $2,0 \%$ & $-19,1 \%$ \\
\hline $3,0 \%$ & $-19,1 \%$ \\
\hline $4,0 \%$ & $-19,2 \%$ \\
\hline $5,0 \%$ & $-19,3 \%$ \\
\hline $6,0 \%$ & $-19,5 \%$ \\
\hline $7,0 \%$ & $-19,6 \%$ \\
\hline $8,0 \%$ & $-19,7 \%$ \\
\hline $9,0 \%$ & $-19,9 \%$ \\
\hline $10,0 \%$ & $-20,1 \%$ \\
\hline $11,0 \%$ & $-20,3 \%$ \\
\hline $12,0 \%$ & $-20,5 \%$ \\
\hline $13,0 \%$ & $-20,7 \%$ \\
\hline $14,0 \%$ & $-21,0 \%$ \\
\hline $15,0 \%$ & $-21,3 \%$ \\
\hline $16,0 \%$ & $-21,5 \%$ \\
\hline $17,0 \%$ & $-21,8 \%$ \\
\hline $18,0 \%$ & $-22,2 \%$ \\
\hline $19,0 \%$ & $-22,5 \%$ \\
\hline & \\
\hline
\end{tabular}

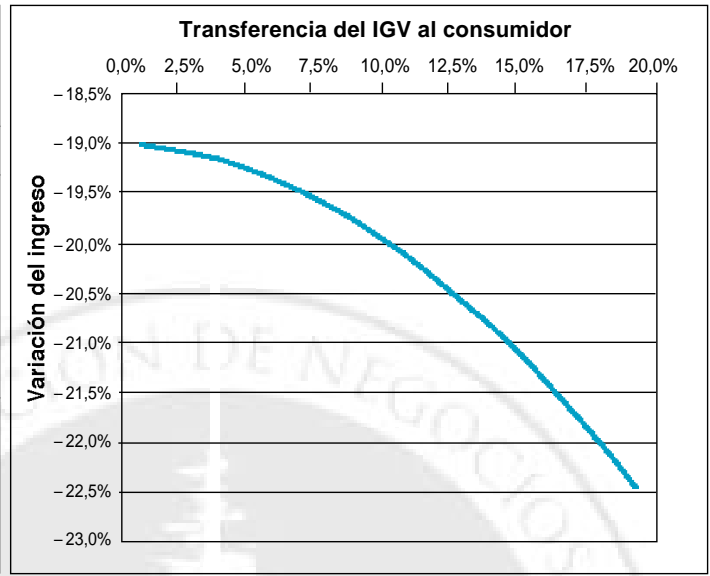

\section{Crecimiento de los ingresos por niveles de IGV \\ Gráfico 5}

ocupación), lo que demuestra que la curva de demanda que enfrentan las empresas formales del sector es muy elástica. Así, se calcula que la caída de la demanda sería prácticamente proporcional al incremento del precio, lo que significa que las empresas formales verían perder de manera creciente su participación en el mercado a medida que eleven sus precios -o intenten transferir el IGV a los consumidores-.

Para demostrar que las empresas formales perderían más si intentaran que el IGV fuera pagado íntegramente por los usuarios, se estima, en primer lugar, los ingresos de la empresa (multiplicando la tarifa por el nivel de ocupación) y, en segundo lugar, el crecimiento porcentual de estos ingresos frente al crecimiento porcentual de la tarifa.

De acuerdo con el gráfico 5, si la transferencia del IGV al consumidor final es nula, es decir, la empresa asume todo el IGV, el nivel de ingreso de la empresa caería en $19 \%$ (en esta sección se abstrae el tema de la recuperación del IGV). Sin embargo, si intenta transferir este tributo al consumidor, la caída de la demanda sería de una proporción mayor al crecimiento del precio, con lo cual los ingresos descenderían aun más. Esta reducción de los ingresos sería cada vez mayor a medida que la empresa intente transferir el IGV al usuario final.

Transferir todo el IGV al usuario significaría una reducción de los ingresos totales de las empresas en $22,5 \%$, ya que los usuarios pasarían del sector formal al informal. Se estima que el nivel de ocupación de las unidades formales descendería de $84 \%$ a $68 \%$, reflejándose en una caída de los ingresos en el monto anotado.

La lección es clara: para reducir la pérdida, que de todas maneras significa la 
aplicación del IGV, la empresa formal deberá asumir el íntegro de este impuesto. Si intenta que el usuario lo pague, le irá peor.

En condiciones normales la demanda por servicios públicos, como el servicio de transporte, presenta una elasticidad precio entre 0 y -1 , con lo cual, un incremento de la tarifa genera una reducción proporcionalmente menor de la demanda ${ }^{4}$. Sin embargo, esto no parece ser cierto en el presente caso.

En la medida en que la menor o mayor elasticidad depende de la existencia de bienes o servicios sustitutos, es claro que este supuesto (elasticidad entre $0 \mathrm{y}-$ 1) no es una premisa teórica, a priori, sino más bien una evidencia empírica, resultado de las características de los mercados. Entonces, la pregunta es: ¿por qué sucede esto?, es decir, ¿por qué la elasticidad precio es bastante elevada?

La respuesta está en que hay una gran informalidad en el sector, a raíz de la aplicación, en la década pasada, de una extrema liberalización y desregulación en este mercado. La competencia desleal de las empresas informales (expresada en la evasión de controles, tributos, normas técnicas y de seguridad, etc.) hace que la demanda que enfrentan las empresas formales sea anormalmente elástica, debido a que sus servicios son percibidos por los usuarios como iguales o similares a los de

4. Un estudio realizado por el INEI (1996) con una metodología y definiciones distintas, estimó que la demanda por el servicio de transporte era inelástica en los niveles socioeconómicos altos, dependiendo del tipo de servicio involucrado: $-0,01$, en el caso del transporte interprovincial, $-0,22$, en el servicio de taxi, $-0,48$, en el colectivo y $-0,49$, en el caso del uso de transporte particular. los informales, situación que no corresponde a la realidad.

En este contexto de mercado, la aplicación del IGV al servicio de transporte interprovincial de pasajeros estaría, en la práctica, convirtiéndose en una medida confiscatoria, ya que esta carga tributaria sería asumida por el productor, al no tener otra alternativa.

\subsubsection{La informalidad como factor dis- torsionante del mercado}

El mercado de transporte terrestre de pasajeros se reconfiguró a inicios de la década pasada con el D.L. 640, que estableció el libre acceso al mercado, y el D.L. 642 , que decretó la libre competencia de tarifas. En esta situación de falta de regulación y control por parte del Estado, se generó un proceso de «competencia perversa», que a través de la informalización de las actividades y sobreoferta del servicio conformó un mercado con tarifas predatorias, creciente evasión fiscal, ineficiencia e inseguridad del servicio, contaminación ambiental, etc.

Así, por ejemplo, el número de ómnibus (para todo tipo de transporte) aumentó de 20 mil unidades en 1990 a casi 50 mil en el 2002, estimándose una sobreoferta del orden de $40 \%$. En el mismo periodo, el número de accidentes en carreteras creció de mil a casi 3 mil por año, lo que arroja un nivel de siniestralidad muy elevado 5 .

5. A nivel sudamericano, Colombia tiene la estadística de muertes por accidente de tránsito (por cada 10 mil vehículos) más elevada (58), seguida de Perú (32), Venezuela (24), Paraguay (23), Bolivia (21), Chile (20), Brasil (8) y Argentina (6). Los estándares de los países industrializados están entre 1 y 2 muertes por cada 10 mil vehículos. 
En términos simplificados, los problemas de falta de regulación y control del servicio de transporte generaron que la competencia en el sector básicamente se canalice a través de menores tarifas. Dada la sobreoferta de unidades, esto significó el deterioro de la calidad y seguridad del servicio, resultado directo de la pobre rentabilidad del negocio (Ramírez, 2003).

En este esquema conceptual, la creciente informalidad en el servicio de transporte de pasajeros afecta a la demanda que enfrentan las empresas formales, debido a que los servicios de unas y otras son percibidos por el público como similares o sustitutos perfectos, razón por la cual la estrategia basada en menores precios del sector informal compite, desleal y ventajosamente con la estrategia del sector formal, basada tanto en calidad como en precio. Así, a medida que la tarifa de las empresas informales decrece, como parte de su estrategia de mercado, la demanda que enfrentan las empresas formales también cae. La evidencia parece apuntar a que la caída de la demanda del sector formal es proporcionalmente mayor que la caída de la tarifa del sector informal, por lo que este último ha ido en aumento en los últimos años.

El inconveniente detrás de esta solución de mercado se encuentra en la elección del consumidor. Reiteramos que tanto los servicios de transporte formal como el informal son percibidos por los usuarios como iguales, debido a una fuerte asimetría de la información y a la pobre valoración que se confiere a la calidad y seguridad del servicio. En este sentido, la función reguladora del Estado (que en la actualidad no cumple) debería definir, por lo menos, un nivel mínimo en la calidad del servicio para que los usuarios elijan, a través de los mecanismos de mercado, qué servicio es el más económico en servicios más o menos estandarizados.

Las empresas informales trazan una estrategia de precios bajos ya que su «ventaja competitiva» reside, fundamentalmente, en su capacidad de evadir la mayoría de los impuestos, aportes sociales y controles técnicos que afronta la actividad formal. Lamentablemente, esta capacidad de evasión va en detrimento de la calidad, seguridad y eficiencia del servicio, por lo que genera una solución de mercado perversa y ruinosa socialmente.

En general, la atomización del sector informal en empresas casi unipersonales ${ }^{6}$ hace difícil a la Sunat el seguimiento de sus movimientos económicos; en la práctica su fiscalización es muy onerosa. Así, la autoridad prefiere y ejecuta acciones dirigidas sólo hacia las empresas formales. A continuación se detallan algunos de los mecanismos de evasión observados entre las empresas informales del sector.

- ISC a los combustibles.-Si bien el impuesto selectivo al consumo de combustibles lo pagan las empresas distribuidoras de hidrocarburos (Petroperú y grifos), se conoce de transportistas que se abastecen de petróleo de dudosa procedencia ${ }^{7}$, cuyos precios son menores y están «libres de impuestos». Una particularidad del informal es que no requiere necesariamente comprobantes de pago, ya que

6. El $60 \%$ de las empresas de transporte cuentan con 5 o menos unidades, mientras el $80 \%$ cuenta con 10 o menos.

7. Combustible sustraído de instituciones públicas, robado de empresas transportistas formales o «importado» de regiones exoneradas de impuestos. 
su empresa no lleva contabilidad o, si la lleva por apariencia, no registra el total de sus operaciones.

- Aranceles.- Una manera de abaratar la compra de vehículos y, por lo tanto, evadir aranceles y otros tributos, es adquirir los llamados camiones-buses, que se construyen de una carrocería de ómnibus montada sobre el chasis de un camión. Un camión-bus, que puede tener hasta dos pisos, cuesta alrededor de 80 mil dólares, mientras el vehículo específicamente diseñado para el transporte de pasajeros vale más de 350 mil dólares. Obviamente, este abaratamiento en los costos afecta la seguridad de la población, ya que esta unidad transformada no es adecuada para brindar el servicio de transporte de pasajeros. Respecto a repuestos y otros materiales, un transportista informal, especialmente si no lleva contabilidad, no tiene reparo en adquirir repuestos de contrabando o de dudosa procedencia, por lo que la evasión de aranceles e impuestos se hace efectiva.

- $I G V$.- Lo usual en el sector informal es que las compras de repuestos y reparaciones diversas de los vehículos se realicen sin factura; en consecuencia, el abaratamiento de los costos tiene un correlato directo en la falta de garantía de la reparación y en la inseguridad de los ómnibus.

- Aportaciones y leyes sociales.- Es común observar choferes que cobran sus remuneraciones con recibos por honorarios profesionales o bajo la modalidad de comisión (será por ello que el número de choferes inscritos en el registro correspondiente del MTC es menor que el número de unidades de transporte). La mayoría de las empresas informales no tienen empleados o, si los tienen, los contratan de forma ilegal, por lo que sus trabajadores se encuentran al margen de la mayoría de los beneficios laborales (seguro, pensiones, vacaciones, etc.).

- Utilidades para los trabajadores.-Al llevar una contabilidad de manera informal, si la llevan, lo más probable es que las empresas informales nunca «obtengan» utilidades, de modo que los trabajadores que eventualmente figuran en planilla no tienen acceso al reparto de utilidades.

- Peajes.-La posibilidad de evasión de peajes es significativa en el caso de las unidades informales, ya que éstas no siempre exigirán comprobantes para llevar adecuadamente su contabilidad.

- Contribuciones municipales.-La mayor parte de transportistas informales no invierten en infraestructura, es decir, no poseen terminales, talleres ni instalaciones que impliquen mayores inversiones y costos. Más aún, quienes trabajan a comisión u otros transportistas no tienen ni siquiera domicilio conocido, menos oficinas.

- Impuesto a la renta.- La clonación de placas $^{8}$, los comisionistas ${ }^{9}$, las contabilidades dudosas, la ausencia de do-

8. Dos o más unidades ilegales usan el mismo número de placa que una unidad formal que goza de todos los permisos y licencias.

9. Se conoce así al caso en que una empresa de transporte que goza de una concesión de ruta legal adquiere simuladamente unidades de un propietario de ómnibus que quiere ingresar al negocio pero no tiene posibilidades de obtener 
micilios conocidos, entre otros, son mecanismos empleados por los informales para evadir el impuesto a la renta.

- Derecho de emisión de pólizas de seguros.- Los informales no cumplen con las disposiciones sobre seguros. Muchos informales adquieren ilegalmente calcomanías del SOAT, lo que se corrobora con el gran número de accidentes cuya responsabilidad finalmente nadie asume.

\subsection{Impacto sobre la rentabilidad de las empresas}

En la presente sección se analiza el impacto de la aplicación del IGV sobre la rentabilidad de las empresas del sector, para lo cual se desarrolla modelos de simulación, tanto entre las empresas formales como entre las informales. Para realizar estas evaluaciones se trabaja con la estructura de costos estimada en la sección anterior y se asume que la mejor estrategia para las empresas formales es no incrementar la tarifa de transporte, lo que significa asumir el íntegro del IGV.

\subsubsection{Empresas formales}

A partir del 17 de junio de 2003, y bajo el D.S. N. ${ }^{\circ} 08242003-E F$, se eliminó la exoneración del IGV a los pasajes interprovinciales, lo que significó la entrada en vigencia de la aplicación del crédito fiscal sobre los gastos realizados, pero sólo sobre los bienes y servicios adquiridos a partir de esa fecha.

Para estimar el impacto de esta medida se parte de la estructura de costos calculada en la sección anterior, de la cual se deriva que los costos totales representan el $97 \%$ de las ventas (se asume un correlato monetario en dólares análogo a la estructura de costos, en términos absolutos); los ítem destacables, por grandes grupos, se presentan en el cuadro 5. Por ejemplo, los Gastos de personal corresponden a la suma de los rubros $1,2,12,13$ y 14 del cuadro 1, mientras Otros gastos no afectos al IGV resultan de sumar los rubros 3 , 18,19 y 23 .

Luego se reproduce (ver cuadro 6) la situación inicial del flujo de caja y el es-

\section{Cuadro 5}

Estructura de costos simplificada

\begin{tabular}{|l|r|r|r|}
\hline & Ítem del cuadro 1 & US\$ & \% \\
\hline Compras (incluido IGV) & $4,5,6,7,8,9,11,15,16,17,20,21,24$ & 59,13 & 60,93 \\
Gastos financieros & 22 & 4,30 & 4,43 \\
Gastos de personal & $1,2,12,13,14$ & 13,33 & 13,74 \\
Otros gastos no afectos al IGV & $3,18,19,23$ & 7,40 & 7,63 \\
Depreciación & 10 & 12,88 & 13,27 \\
\hline Total costos & & $\mathbf{9 7 , 0 4}$ & $\mathbf{1 0 0 , 0 0}$ \\
\hline
\end{tabular}

una concesión. Luego de tramitada la inclusión del vehículo al MTC, la empresa formal vuel- ve a transferir la propiedad del ómnibus a su dueño original. 
tado de pérdidas y ganancias de las empresas formales del sector. En el caso del estado de ganancias y pérdidas, se toman los valores en dólares del cuadro 5, mientras en el flujo de caja se excluye la depreciación. Es importante anotar que como en la situación inicial el servicio de transporte estaba exonerado del IGV, no hay crédito fiscal por el IGV pagado en las compras ni el depósito por el diferencial del IGV.

Los resultados del estado de ganancias y pérdidas indican que se viene obteniendo una utilidad bruta equivalente a $2,96 \%$ de los ingresos, aproximadamente $980 \mathrm{mil}$ dólares, dado que para las cuatro empresas analizadas los ingresos ascienden a 33

\section{Cuadro 6}

Flujo de caja y estado de ganancias y pérdidas Situación inicial

\begin{tabular}{|lr|}
\hline Flujo de caja & $\%$ \\
\hline Valor venta & 100,00 \\
IGV & 0,00 \\
\hline Total ingresos & $\mathbf{1 0 0 , 0 0}$ \\
\hline Compras & 59,13 \\
IGV (crédito fiscal) & 0,00 \\
Depósito IGV diferencial & 0,00 \\
Gastos financieros & 4,30 \\
Otros gastos no afectos al IGV & 7,40 \\
Personal & 13,33 \\
\hline Total egresos & $\mathbf{8 4 , 1 6}$ \\
\hline Impuesto a la renta & 0,76 \\
Participación de trabajadores & $\mathbf{0 , 1 5}$ \\
Caja neta anual & 14,93 \\
\hline & $\mathbf{U S} \$$ \\
\hline Ganancias y pérdidas & $\mathbf{1 0 0 , 0 0}$ \\
\hline Ingresos & 59,13 \\
\hline Compras & 4,30 \\
\hline Gastos financieros & 7,40 \\
Otros gastos no afectos al IGV & 13,33 \\
Personal & 12,88 \\
\hline Depreciación & $\mathbf{9 7 , 0 4}$ \\
\hline Total costos & 0,15 \\
\hline Utilidad bruta & 2,20 \\
\hline Participación de trabajadores & $3,41 \%$ \\
\hline Impuesto a la renta & \\
\hline Utilidad neta & \\
Rentabilidad sobre activos & \\
\hline & \\
\hline
\end{tabular}




\section{Cuadro 7 \\ Flujo de caja y estado de pérdidas y ganancias (\%)}

\begin{tabular}{|l|c|c|}
\hline Flujo de caja & Situación inicial & Simulación \\
\hline Valor venta & 100,00 & 84,03 \\
IGV & 0,00 & 15,97 \\
\hline Total ingresos & $\mathbf{1 0 0 , 0 0}$ & $\mathbf{1 0 0 , 0 0}$ \\
\hline Compras & 59,13 & 49,69 \\
IGV (crédito fiscal) & 0,00 & 9,44 \\
Depósito IGV diferencial & 0,00 & 6,53 \\
Gastos financieros & 4,30 & 4,30 \\
Otros gastos no afectos al IGV & 7,40 & 7,40 \\
Personal & 13,33 & 13,33 \\
\hline Total egresos & $\mathbf{8 4 , 1 6}$ & $\mathbf{9 0 , 6 9}$ \\
\hline Impuesto a la renta & 0,76 & 0,00 \\
\hline Participación trabajadores & $\mathbf{0 , 1 5}$ & 0,00 \\
\hline Caja neta anual & 14,93 & 9,31 \\
\hline
\end{tabular}

\begin{tabular}{|lrr|}
\hline Ganancias y pérdidas & & \\
\hline Ingresos & $\mathbf{1 0 0 , 0 0}$ & $\mathbf{8 4 , 0 3}$ \\
Compras & 59,13 & 49,69 \\
Gastos financieros & 4,30 & 4,30 \\
Otros gastos no afectos al IGV & 7,40 & 7,40 \\
Personal & 13,33 & 13,33 \\
Depreciación & 12,88 & 12,88 \\
\hline Total costos & 97,04 & 87,60 \\
\hline Utilidad bruta* & $\mathbf{2 , 9 6}$ & $-\mathbf{3 , 5 7}$ \\
\hline Impuesto a la renta & 0,76 & 0,00 \\
Utilidad neta* & 2,20 & $-3,57$ \\
Rentabilidad sobre activos & $3,41 \%$ & $-5,54 \%$ \\
\hline
\end{tabular}

* A diferencia del cuadro 1, en donde el concepto de utilidad se define en términos de la incidencia tributaria, en estas simulaciones se ha utilizado el concepto económico de utilidad, en donde se «netean» las pérdidas.

millones de dólares (cuadro 1). Por su parte, la utilidad neta, equivalente a $2,2 \%$ de los ingresos, dividida entre el valor de los activos ${ }^{10}$ arroja una rentabilidad de $3,41 \%$.

10. Dada la depreciación de $12,88 \%$ de los ingresos del cuadro 1 , se asume una vida útil de cinco años para estimar el valor del patrimonio
Si se revisan los datos del cuadro 6 resalta el hecho de que el negocio de transporte presenta un flujo de caja muy favorable, pero una rentabilidad muy baja, esto es, una vez descontada la depreciación del

de las empresas. El valor estimado es de 21,29 millones de dólares. 
capital. En otras palabras, este negocio proporciona una fuerte liquidez al transportista, pero la rentabilidad es tan baja que la recuperación del capital es lenta (si llega a recuperarlo). Esta característica del negocio suele ser perversa para el inversionista, pues interpreta el flujo de caja como indicador de rentabilidad sin percatarse de que progresivamente «se está comiendo» su capital al no reponer su inversión inicial.

Para simular el impacto del IGV en el corto plazo, se entiende por corto plazo, siguiendo el concepto económico, al periodo en el cual no se realizan nuevas inversiones de capital (en este caso ómnibus), por lo que no hay la posibilidad de recuperar el IGV pagado por la eventual compra de unidades vehiculares. De igual manera, tampoco se puede recuperar el IGV de las unidades ya adquiridas, dado que éste ya está incluido como costo en el valor del activo y será recuperado con la depreciación anual (como se venía haciendo hasta entonces). Así, a partir de la fecha sólo se recuperará como crédito fiscal el IGV pagado en las compras corrientes. Atendiendo a las cifras, hasta un máximo de $19 \%$ de 59,13 .

En la sección anterior se demostró que, dada las condiciones del mercado, el nuevo equilibrio por la aplicación del IGV se alcanzaría si la empresa formal asume el íntegro de este impuesto, por lo que el precio al consumidor se mantendría y la empresa sacrificaría su margen de ganancia. El cuadro 7 muestra el impacto sobre el flujo de caja y el estado de pérdidas y ganancias que tal decisión generaría en el corto plazo.

En cuanto al flujo de caja, la aplicación del IGV significaría que el nuevo valor de venta ya no sería 100, sino 84,03, mientras el IGV sería 15,97, que es el $19 \%$ de 84,03 . Por el lado de las compras, el original 59,13 (con IGV) se desagrega en 49,69 ( $\sin$ IGV) y 9,44 de IGV (19\% de $49,69)$, con lo cual «el depósito IGV diferencial» o monto por depositar a la Sunat por el IGV recaudado por la venta de pasajes, sería 6,53 (15,97-9,44). En esta situación, los egresos de caja aumentarían de 84,16 a 90,69, es decir, crecerían en el monto de los depósitos a la Sunat.

Respecto al estado de ganancias y pérdidas, se observa que los ingresos caerían a 84,03 , mientras los costos llegarían a 87,60 , por lo que la utilidad bruta caería de un saldo positivo de $2,96 \%$ de los ingresos a un déficit de $3,57 \%$. En términos monetarios, esto significa que la utilidad bruta pasaría de ser positiva en 980 mil dólares a ser negativa en 900 mil dólares (33 millones*84,03\%*3,57\%), es decir, las cuatro empresas formales perderían, en conjunto, 1,88 millones de dólares, en comparación con la situación inicial, dato sumamente grave para la continuidad del negocio formal.

Los resultados proyectados son categóricos. La aplicación del IGV a los pasajes causa que el negocio formal sea insostenible en el tiempo, por la competencia desleal de las empresas informales y la determinación, por mecanismos de mercado, de tarifas predatorias ${ }^{11}$. Obviamente, todo este proceso va en desmedro del servicio.

11. Según la definición del Reglamento Nacional de Administración de Transportes, tarifa predatoria es aquella que está por debajo de los costos operativos reales y atenta contra las condiciones de seguridad y calidad del servicio. 


\subsubsection{Empresas informales}

Con el objetivo de hacer explícitas las ventajas que tendría una empresa informal frente a una formal, a continuación se desarrolla una sencilla simulación de una empresa informal.

Por el lado de los costos, esta empresa no paga cargas sociales, compra insumos más baratos que sus competidoras formales (aunque de menor calidad), compra con IGV una fracción de lo que adquiere una empresa formal y tiene una menor depreciación de capital al adquirir vehículos más económicos, ya sea porque evade tributos o porque compra unidades transformadas (camión-bus). No obstante, esta empresa debe asumir un mayor costo financiero debido al carácter informal de su organización. Específicamente, se simula la empresa informal bajo los siguientes supuestos:

- Evade el pago de las cargas sociales y laborales, con lo cual el gasto de personal de esta empresa informal se reduciría a 9,44, mientras la empresa formal gasta en este rubro 13,33.

- Las compras representarían aproximadamente el $80 \%$ de las realizadas por una empresa formal. El rubro «compras» de la empresa informal sería de 47,85 , mientras en la empresa formal ascendería a 59,13.

- Sólo paga IGV sobre la tercera parte de las compras efectuadas, de modo que el crédito fiscal disponible llegaría a $2,85(45 / 3 * 19 \%)$.

- La depreciación del capital disminuiría a 8,59, monto equivalente a las dos terceras partes de lo considerado para la empresa formal.

- Los gastos financieros aumentarían en un punto porcentual.
Por el lado de los ingresos, se supone que en el escenario inicial las tarifas del sector informal son iguales al $80 \%$ de las tarifas del sector formal, como estrategia de negocio. Para el caso de la simulación (con IGV), se supone que el sector informal mantendría esta estrategia de precios al consumidor, por lo que asumiría «contablemente» o facturaría con IGV hasta un monto que le permita recuperar el IGV pagado por los insumos comprados, es decir, hasta llegar a 2,85. Esto significaría que el $81 \%$ de los pasajes se continuarían vendiendo de manera informal -y por lo tanto sin $\mathrm{IGV}_{-}$, mientras el restante $19 \%$ se facturaría con IGV. En neto, la empresa informal obtendría un monto de ingresos o valor de venta de 77,15 , que es el promedio ponderado de lo que vende con IGV y $\sin$ IGV.

Es importante anotar que en este caso la aplicación del IGV no afectaría al pasaje cobrado por las empresas informales al usuario final, pero sí impactaría negativamente sobre el ingreso o valor de venta. Si se comparan estos resultados con los proyectados para las empresas formales, se estima que la aplicación del IGV no variaría la relación de precios de las empresas formales e informales, que se mantendría en 80/100 (80\%). En cambio, respecto al valor de venta, la aplicación del IGV al pasaje interprovincial disminuiría la diferencia entre los ingresos de las empresas informales y los ingresos de las formales; de una relación 80/100 (80\%) se pasaría a una relación de $77,15 / 84,03$ (92\%). En este sentido, la aplicación del IGV a los pasajes favorecería a las empresas informales.

El cuadro 8 muestra que la empresa informal obtendría un flujo de caja similar en la situación inicial ( $\sin$ IGV a los 


\section{Cuadro 8 \\ Flujo de caja (\%)}

\begin{tabular}{|l|r|r|r|r|}
\hline \multirow{2}{*}{} & \multicolumn{2}{|c|}{ SITUACIÓN INICIAL } & \multicolumn{2}{c|}{ SIMULACIÓN } \\
\cline { 2 - 5 } & $\begin{array}{c}\text { Empresa } \\
\text { formal }\end{array}$ & $\begin{array}{c}\text { Empresa } \\
\text { informal }\end{array}$ & $\begin{array}{c}\text { Empresa } \\
\text { formal }\end{array}$ & $\begin{array}{r}\text { Empresa } \\
\text { informal }\end{array}$ \\
\hline VALOR VENTA & 100,00 & 80,00 & 84,03 & 77,15 \\
IGV & 0,00 & 0,00 & 15,97 & 2,85 \\
\hline Total ingresos & $\mathbf{1 0 0 , 0 0}$ & $\mathbf{8 0 , 0 0}$ & $\mathbf{1 0 0 , 0 0}$ & $\mathbf{8 0 , 0 0}$ \\
\hline COMPRAS & 59,13 & $\mathbf{4 7 , 8 5}$ & 49,69 & $\mathbf{4 5 , 0 0}$ \\
IGV (crédito fiscal) & 0,00 & 0,00 & 9,44 & 2,85 \\
Depósito IGV diferencial & 0,00 & 0,00 & 6,53 & 0,00 \\
Gastos financieros & 4,30 & 5,30 & 4,30 & 5,30 \\
Otros gastos no afectos al IGV & 7,40 & 7,40 & 7,40 & 7,40 \\
Personal & 13,33 & $\mathbf{9 , 4 4}$ & 13,33 & $\mathbf{9 , 4 4}$ \\
\hline Total egresos & $\mathbf{8 4 , 1 6}$ & $\mathbf{6 9 , 9 9}$ & $\mathbf{9 0 , 6 9}$ & $\mathbf{6 9 , 9 9}$ \\
\hline Impuesto a la renta & 0,76 & 0,37 & 0,00 & 0,37 \\
\hline Participación de los trabajadores & $\mathbf{0 , 1 5}$ & $\mathbf{0 , 0 0}$ & $\mathbf{0 , 0 0}$ & $\mathbf{0 , 0 0}$ \\
\hline Caja neta anual & 14,93 & 9,64 & 9,31 & $\mathbf{9 , 6 4}$ \\
\hline
\end{tabular}

pasajes) y en la simulada (con IGV a los pasajes); en cambio, las empresas formales sufrirían un grave deterioro. La ventaja competitiva que genera la evasión de impuestos, cargas laborales y sociales y otros tributos permitiría a las empresas informales una mayor capacidad para asumir el IGV a los pasajes. Se calcula que la aplicación del IGV al STTIP significaría para una empresa formal la reducción de su flujo de caja neto en $37,6 \%$; en cambio, para las empresas informales, esta medida carecería de importancia, sería indiferente.

Igualmente, los indicadores del estado de ganancias y pérdidas (cuadro 9), ilustran las ventajas de las empresas informales. La aplicación del IGV originaría la caída de la rentabilidad sobre activos de las empresas formales, de $+3,4 \%$ a $-5,5 \%$, pero no afectaría la rentabilidad de las empresas informales, la que se mantendría en $1,6 \%$.

En general, se observa que las empresas informales tienen claras ventajas de evasión de impuestos, de aportes sociales y otros, que les permiten afrontar con cierta mayor holgura la asunción de parte del IGV y su posterior descargo fiscal; lo que las empresas formales no están en capacidad de hacer.

La gravedad de estos resultados se acentúa si se considera, grosso modo, que actualmente el sector formal sólo representa el $20 \%$ del mercado, en tanto el informal cubre el $80 \%$. Obviamente, la propuesta del cobro del IGV pondría en peligro la viabilidad de las empresas formales en el mediano plazo, lo que, eventualmente, podría llevar a su desaparición. 


\section{Cuadro 9 \\ Estado de ganancias y pérdidas (\%)}

\begin{tabular}{|l|r|r|r|r|}
\hline \multirow{2}{*}{} & \multicolumn{2}{|c|}{ SITUACIÓN INICIAL } & \multicolumn{2}{c|}{ SIMULACIÓN } \\
\cline { 2 - 5 } & $\begin{array}{c}\text { Empresa } \\
\text { formal }\end{array}$ & $\begin{array}{c}\text { Empresa } \\
\text { informal }\end{array}$ & $\begin{array}{c}\text { Empresa } \\
\text { formal }\end{array}$ & $\begin{array}{c}\text { Empresa } \\
\text { informal }\end{array}$ \\
\hline Ingresos & $\mathbf{1 0 0 , 0 0}$ & $\mathbf{8 0 , 0 0}$ & $\mathbf{8 4 , 0 3}$ & $\mathbf{7 7 , 1 5}$ \\
\hline Compras & 59,13 & 47,85 & 49,69 & 45,00 \\
Gastos financieros & 4,30 & 5,30 & 4,30 & 5,30 \\
Otros gastos no afectos al IGV & 7,40 & 7,40 & 7,40 & 7,40 \\
Personal & 13,33 & 9,44 & 13,33 & 9,44 \\
Depreciación & 12,88 & 8,59 & 12,88 & 8,59 \\
\hline Total costos & $\mathbf{9 7 , 0 4}$ & $\mathbf{7 8 , 5 8}$ & $\mathbf{8 7 , 6 0}$ & $\mathbf{7 5 , 7 3}$ \\
\hline Utilidad bruta & $\mathbf{2 , 9 6}$ & $\mathbf{1 , 4 2}$ & $-\mathbf{3 , 5 7}$ & $\mathbf{1 , 4 2}$ \\
\hline Impuesto a la renta & 0,76 & 0,37 & 0,00 & 0,37 \\
Utilidad neta & 2,20 & 1,06 & $-3,57$ & 1,06 \\
Rentabilidad sobre activos & $3,4 \%$ & $1,6 \%$ & $-5,5 \%$ & $1,6 \%$ \\
\hline
\end{tabular}

\subsection{Impacto sobre la incidencia tributaria y la recaudación}

Utilizando el modelo de costeo y análisis de incidencia tributaria ya presentado, en esta sección se recalcula cada uno de los ítem que están afectos a impuestos y/o cargas laborales y sociales, considerando su peso relativo sobre los ingresos y la correspondiente tasa impositiva. De esta manera, se estima que la nueva incidencia tributaria crecería de $25,75 \%$ a $27,52 \%$ (ver cuadro 10). Obviamente, este cálculo se efectúa sobre una nueva base de ingresos que, por efecto de la aplicación del IGV a los pasajes se reduce en 19\% (de 100 a $84,04 \%$ ), lo que significa que la mayor incidencia tributaria no implica mayor recaudación: el $27,52 \%$ de 84,04 es menor al 25,75\% de 100.

En este caso, los ítem 25 y 26 caerían significativamente, debido a que el IGV a los pasajes asumido por la empresa afec- taría la utilidad y, por lo tanto, se pagaría menor impuesto a la renta y habría menor reparto de utilidades. Asimismo, se eliminaría el ítem 24 (IGV no utilizado), ya que en esta situación sería posible recuperar este impuesto con el crédito fiscal. No obstante, se debe agregar el IGV depositado a la Sunat, correspondiente al IGV de los pasajes no usado como crédito fiscal (ítem 28). En síntesis, la menor recaudación se generaría fundamentalmente por el menor monto del impuesto a la renta y porque una buena parte del IGV al pasaje sería utilizado como crédito fiscal.

Con la aplicación del IGV a los pasajes y la asunción íntegra de este tributo por parte del transportista, los ingresos netos de la empresa formal se reducirían en $19 \%$. La nueva base ya no serían los 33 millones de dólares en ventas de las cuatro empresas consideradas, sino sólo 27,7 millones de dólares. De esta manera, la recaudación caería de 8,5 millones 


\section{Cuadro 10 \\ Incidencia tributaria en el sector formal (\%)}

\begin{tabular}{|c|c|c|}
\hline & $\begin{array}{c}\text { Situación } \\
\text { inicial sin IGV }\end{array}$ & $\begin{array}{l}\text { Simulación } \\
\text { con IGV }\end{array}$ \\
\hline $\begin{array}{l}\text { Gastos de operación } \\
1 \text { Remuneraciones de choferes, ayudantes, } \\
\text { supervisores, etc. } \\
2 \text { CTS, EsSalud, IES, aguinaldos, vacaciones y otros } \\
3 \text { Peajes } \\
4 \text { Combustibles } \\
5 \text { Lubricantes } \\
6 \text { Repuestos } \\
7 \text { Neumáticos, cámaras y ponchos } \\
8 \text { Reparación y mantenimiento } \\
9 \text { Seguros } \\
10 \text { Depreciación } \\
11 \text { Otros gastos de operación } \\
\quad \text { Subtotal }\end{array}$ & $\begin{array}{r}0,00 \% \\
2,20 \% \\
3,03 \% \\
6,95 \% \\
0,06 \% \\
0,43 \% \\
0,14 \% \\
0,00 \% \\
0,05 \% \\
1,38 \% \\
0,00 \% \\
14,27 \%\end{array}$ & $\begin{array}{r}0,00 \% \\
2,61 \% \\
3,61 \% \\
7,97 \% \\
0,07 \% \\
0,50 \% \\
0,16 \% \\
0,00 \% \\
0,05 \% \\
1,64 \% \\
0,00 \% \\
16,62 \%\end{array}$ \\
\hline $\begin{array}{l}\text { Gastos administrativos } \\
12 \text { Sueldos } \\
13 \text { CTS, EsSalud, IES, aguinaldos, vacaciones y otros } \\
14 \text { Honorarios profesionales } \\
15 \text { Servicios prestados por terceros } \\
16 \text { Útiles de escritorio } \\
17 \text { Mantenimiento local } \\
18 \text { Depreciación activos administrados } \\
19 \text { Alquileres de oficinas } \\
20 \text { Seguros } \\
21 \text { Otros gastos (se asume constante, gasto fijo) } \\
\quad \text { Subtotal }\end{array}$ & $\begin{array}{l}0,00 \% \\
1,69 \% \\
0,00 \% \\
0,00 \% \\
0,00 \% \\
0,00 \% \\
0,00 \% \\
0,00 \% \\
0,00 \% \\
0,73 \% \\
2,43 \%\end{array}$ & $\begin{array}{l}0,00 \% \\
2,01 \% \\
0,00 \% \\
0,00 \% \\
0,00 \% \\
0,00 \% \\
0,00 \% \\
0,00 \% \\
0,00 \% \\
0,73 \% \\
\mathbf{2 , 7 4 \%}\end{array}$ \\
\hline $\begin{array}{l}\text { Gastos finacieros } \\
22 \text { Gastos financieros }\end{array}$ & $0,00 \%$ & $0,00 \%$ \\
\hline $\begin{array}{l}\text { Otros gastos/ingresos } \\
23 \text { Otros gastos }\end{array}$ & $0,00 \%$ & $0,00 \%$ \\
\hline 24 IGV no utilizado (costo en operaciones no gravadas) & $7,56 \%$ & $0,00 \%$ \\
\hline Costos totales antes de impuestos & $0,00 \%$ & $0,00 \%$ \\
\hline Utilidad antes de impuestos * & $0,00 \%$ & $0,00 \%$ \\
\hline 25 Participación utilidad trabadores & $0,24 \%$ & $0,06 \%$ \\
\hline Utilidad después de participación de trabajadores & $0,00 \%$ & $0,00 \%$ \\
\hline 26 Impuesto a la renta: $27 \%$ & $1,24 \%$ & $0,32 \%$ \\
\hline Subtotal & $25,75 \%$ & $19,75 \%$ \\
\hline 27 IGV depositado a SUNAT (diferencial) & $0,00 \%$ & $7,77 \%$ \\
\hline 28 Porcentaje de las contribuciones sobre las ventas & $25,75 \%$ & $27,52 \%$ \\
\hline
\end{tabular}

* Utilidad bajo el concepto de incidencia tributaria, es decir, no se consideran las pérdidas. 
de dólares $(25,75 \% * 33$ millones $)$ a 7,6 millones de dólares $(27,52 \% * 27,7$ millones), lo que significaría una reducción de $10,3 \%$. Si se proyectan estos resultados para los siguientes 10 años ${ }^{12}$ (ver gráfico 6), la caída acumulada ascendería aproximadamente a 18 millones de dólares, cifra muy considerable.

Estos resultados no hacen más que demostrar que la aplicación del IGV no sólo sería negativa para las empresas formales, sino también para el propio Estado, que se vería afectado por la menor recaudación.

Obviamente, esta proyección es básicamente estática, ya que no se está simulando la posibilidad de quiebra de las empresas formales, hecho que agravaría la situación del sector y reduciría aún más la recaudación fiscal.

\subsection{Impacto sobre el presupuesto y el bienestar de las familias}

De acuerdo con la elasticidad precio estimada, el presupuesto de las familias no se vería afectado por la aplicación del IGV al pasaje interprovincial porque este impuesto sería absorbido por las empresas formales y por las informales.

No obstante, si se consideran criterios más amplios de evaluación del impacto de esta medida sobre los pobladores, el resultado sería diferente. Si además de los criterios netamente monetarios se incluyen aspectos cualitativos: calidad, riesgo, seguridad del servicio, entre otros, es necesario señalar que habría un marcado deterioro, tanto por la mayor informalidad prevista en el sector como por el grave perjuicio económico causado a las empresas formales.

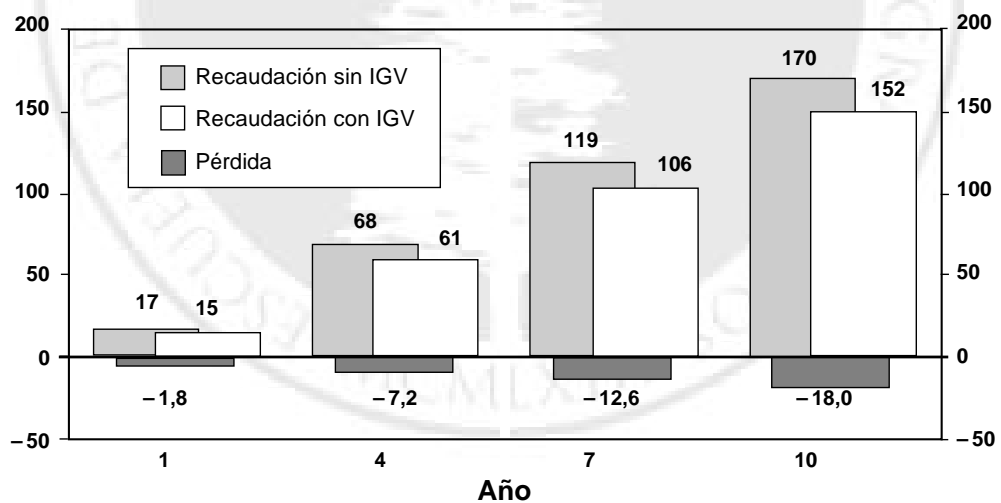

Pérdida en la recaudación por efecto de la aplicación del IGV asumido por el transportista formal (millones de dólares)

Gráfico 6

12. Dado que los ingresos calculados son semestrales, se asume que los ingresos anuales son el doble. Así, la recaudación anual sería 17 millones de dólares sin IGV y 15,2 millones con IGV. 
En cuanto a seguridad, se debe anotar los siguientes peligros a los que estarían expuestos los pasajeros:

- Graves accidentes causados por las características antitécnicas de las unidades transformadas (camión-bus), la falta de mantenimiento, los «estiramientos» antitécnicos o las reparaciones dudosas.

- Graves accidentes causados por la falta de control de rotación y descanso de los choferes.

- Asaltos por las paradas frecuentes de las unidades, la subida de pasajeros sin control adecuado o la falta de paraderos fijos en el lugar de destino.

- Pérdida de pertenencias (equipajes y otros).

- Viajes en vehículos sin cobertura de seguro para pasajeros.

- Viajes en vehículos sin control de velocidad.

En lo que se refiere a la calidad y comodidad del servicio destacan:

- Falta de horarios fijos de salida. Los pasajeros deben esperar hasta que se llene el ómnibus para partir; además, deben soportar que siga parando a lo largo de la ruta.

- Incertidumbre, pues las empresas acostumbran cambiar unilateralmente sus rutas o frecuencia de salidas.

- Incomodidad durante el viaje. Al no haber control sobre la capacidad del vehículo, los pasajeros deben soportar la presencia de pasajeros en el pasadizo (recogidos en la ruta).

- Incomodidad al ser disputado y manipulado por los «jaladores» ${ }^{13}$ en los paraderos informales antes de abordar las unidades.

- Imposibilidad de presentar quejas o reclamos por maltratos de cualquier origen.

\section{Conclusiones}

- El servicio de transporte terrestre interprovincial de pasajeros soporta una elevada carga tributaria -estimada en $26 \%$ de los ingresos- que afecta, fundamentalmente, a las empresas formales del sector. La actividad es especialmente sensible a los impuestos indirectos, como el IGV (aplicado a las compras de materias primas, insumos y bienes de capital) y el ISC a los combustibles.

- Se estima que con la eliminación de la exoneración del IGV a los pasajes interprovinciales, el íntegro del IGV sería asumido por los transportistas formales, por lo que esta medida sería perjudicial no solo para estas empresas, sino también para los usuarios e incluso para el Estado -sería contraproducente para la recaudación fiscal-. Únicamente saldrían beneficiadas las empresas informales del sector.

13. Los «jaladores» son parte importante de la informalidad, pues en la práctica son los que consiguen los pasajeros, fijan el precio del pasaje, imponen la hora de salidad y hasta pueden cambiar la ruta. 
- De acuerdo con las simulaciones realizadas en el estudio, las cuatro empresas formales evaluadas perderían, en conjunto, 1,88 millones de dólares -en comparación con la situación inicial, de exoneración del IGV-, escenario que pondría en riesgo la continuidad del negocio formal.

- Las empresas informales tienen claras ventajas derivadas de la evasión y elusión de tributos, por lo que podrían afrontar con cierta holgura la aplicación del IGV, si es que lo pagan.

- En este contexto de mercado, la aplicación del IGV al servicio de transporte interprovincial de pasajeros se convertiría en la práctica en una medida confiscatoria, ya que esta carga tributaria sería asumida por el productor.

- En la medida en que el IGV sería asumido por los ofertantes del servicio, el presupuesto de las familias no sería afectado. No obstante, si se consideran criterios más amplios de evaluación, es decir, que incluyan no sólo los criterios netamente monetarios sino también aspectos cualitativos, como la calidad del servicio, el riesgo y la seguridad, entre otros elementos, sí habría un marcado perjuicio al usuario, debido a la mayor informalidad prevista en el sector.

- Contra lo que se podría esperar, la aplicación del IGV al transporte terrestre interprovincial de pasajeros afectaría incluso a la recaudación fiscal, fundamentalmente por dos vías:

- Por el menor monto del impuesto a la renta, porque al asumir el ínte- gro del IGV las empresas formales verían reducidas sus utilidades.

- Porque una buena parte del IGV a los pasajes sería utilizado como crédito fiscal y, por lo tanto, no incrementaría la recaudación.

- Los resultados negativos proyectados para las empresas formales del sector se producen, principalmente, porque la competencia desleal de las empresas informales (sobre la base de la evasión de controles, tributos, normas técnicas y de seguridad, etc.) hace que la demanda que enfrentan las empresas formales sea anormalmente elástica, debido a que los servicios de unas y otras empresas son percibidos por los usuarios como iguales o similares, situación que no corresponde a la realidad. La calidad del servicio de las empresas informales es inferior a la de las empresas formales.

- Las empresas informales han trazado una estrategia de precios bajos, ya que su «ventaja competitiva» reside, esencialmente, en su capacidad de evadir la mayoría de los impuestos, aportes sociales y controles técnicos que afronta la actividad formal. Lamentablemente, esta estrategia va en detrimento de la calidad, seguridad y eficiencia del servicio, por lo que genera una solución de mercado perversa y ruinosa socialmente.

- En resumen, a pesar de que el servicio de transporte es una actividad clave para el desarrollo de la competitividad del país, no se aprecia un sistema tributario, ni un ordenamiento legal e institucional coherente con este propósito. En estas circunstancias, la propuesta de eliminar la exoneración del 
IGV al servicio de transporte terrestre interprovincial de pasajeros, sin que esté acompañada por otras medidas que alienten la formalización del sector, no contribuye a lograr el contexto más adecuado.

\section{Recomendaciones}

- Redefinir la función reguladora del Estado en el sector, que en la actualidad no cumple. Por lo menos se deberían fijar niveles mínimos de calidad para el servicio, de modo que los usuarios puedan elegir, a través de los mecanismos del mercado, entre un abanico de propuestas de servicios más o menos estandarizados. Esto implica necesariamente que el Estado deje de lado su actitud complaciente o permisiva y actúe de manera proactiva.

- En cuanto a los tributos, es importante no sólo combatir los diversos mecanismos de evasión de las empresas informales, sino también incentivar la formalización de éstas con dispositivos adecuados. Entre otros, deberían considerarse los siguientes:

- Devolución del IGV de las compras mediante cheque bancario.

- Utilización del peaje como sistema de fiscalización de otros impuestos, incluso como mecanismo de pago a cuenta del impuesto a la renta.

- Devolución de parte (o pago a cuenta del impuesto a la renta) del ISC a los combustibles para las empresas formales.
- Medidas de promoción tributaria para la formalización del sector.

- Es prioritario que el Estado asuma y cumpla su función de fiscalización, ejerciendo un control efectivo sobre las empresas informales del sector, ya que, entre otros problemas, esta abstención impide asegurar a la población un nivel mínimo de calidad y seguridad en el servicio de transporte; y a las empresas, un nivel mínimo de rentabilidad. Al respecto, es preciso considerar lo siguiente:

- Si el Ministerio de Transportes y Comunicaciones fiscalizara el cumplimiento de la legislación vigente, no habría el desorden que crea la informalidad. No se nota el esfuerzo del gobierno por ordenar el transporte; al contrario, la débil fiscalización explican la situación actual.

- Algo similar sucede con el control que debe ejercer la Policía. La acción insuficiente ha originado situaciones de hecho que resultan inadmisibles, como la circulación de varios vehículos con el mismo número de placa, por ejemplo.

- Los transportistas informales -entrevistados para este estudio- han manifestado su interés en que se controle el desorden e incluso están dispuestos a formalizarse; pero con la condición de que la fiscalización sea efectiva y alcance a todas las empresas por igual.

- Una manera de fiscalizar podría ser el establecimiento de controles móviles o fijos en la carretera, a 
cargo de personal honesto y bien entrenado que opere computadoras en línea interconectadas con las sedes. Dada la magnitud del mer- cado de transportes, un mayor control incentivaría la inversión formal y el costo se recuperaría con creces.

\section{Nota de edición}

Finalmente, la eliminación de la exoneración al IGV al transporte terrestre interprovincial de pasajeros estuvo vigente muy poco tiempo. El Decreto Supremo n. 0842003-EF, de junio de 2003, que instituyó esta medida, fue derogado por el Decreto Supremo n. ${ }^{\circ}$ 036-2004-EF, de marzo de 2004, con lo cual este servicio fue reincorporado a la lista de servicios exonerados.

\section{Referencias bibliográficas}

BANCO MUNDIAL. 2000. Perú Policy Notes 2000. Background Papers.

PERÚ. INSTITUTO NACIONAL DE ESTADÍSTICA E INFORMÁTICA. 1996. Elasticidad de la demanda de los principales bienes y servicios consumidos por las familias en Lima Metropolitana. Lima: INEI.

2000. Matrices especiales de la tabla de insumo-producto 1994. Lima, INEI.

2003. Compendio estadístico. Lima: INEI.

PERÚ. MINISTERIO DE ECONOMÍA Y FINANZAS. 2003. Informe situacional y problemática actual del petróleo en el mercado doméstico. Boletín de Transparencia Fiscal: Informe Especial. Lima: MEF.

\section{PERÚ. MINISTERIO DE ENERGÍA Y MI-}

NAS. 2003. Informe mensual upstreamdownstream de las actividades de hidrocarburos (www.minem.gob.pe)
PERÚ. SUPERINTENDENCIA NACIONAL DE ADMINISTRACIÓN TRIBUTARIA. 2003. Compendio de tasas impositivas.

Nota tributaria (diversos números).

2003. Texto único ordenado de la ley del impuesto general a las ventas e impuesto selectivo al consumo. www.sunat.gob.pe

RAMÍREZ, Luis. 2003. El problema del transporte terrestre en el Perú. (mimeo).

ROCA, Santiago y colab. 2002. La Inversión en el Perú 2002-2003: entorno, industrias, regiones, financiamiento y estrategias empresariales. Lima: ESAN.

UNIVERSIDAD DEL PACÍFICO. 2001. Metodología de determinación de costos para el servicio público de transporte de pasajeros en ómnibus. (mimeo). 